\title{
NOVA ECONOMIA INSTITUCIONAL: VERTENTES COMPLEMENTARES
}

\section{RESUMO}

O objetivo, neste artigo, foi compreender como os pressupostos teóricos do nível microanalítico da Nova Economia Institucional (NEI), abrangendo notadamente a Economia dos Custos de Transação (TCT) e a Economia dos Custos de Mensuração (ECM), associados à Visão Baseada em Recursos (VBR), podem ser considerados na compreensão dos limites da firma. Por meio de uma pesquisa bibliográfica, os resultados demonstraram que, ao se analisar conjuntamente essas abordagens, fica evidente que a posse e sustentação de recursos estratégicos (VBR) indicam a necessidade de proteger seus direitos de propriedade por meio de mecanismos legais (ECT e ECM) que minimizem a sua perda de valor. Conclui-se que, em última instância, a sustentação de vantagens competitivas se dará por estruturas de governança que considerem a presença de ativos específicos (ECT), sua mensurabilidade (ECM) e a sua condição de competitividade (VBR).

Palavras-chave: Economia dos Custos de Mensuração; Economia dos Custos de Transação; Estruturas de Governança; Visão Baseada em Recursos.

\section{NEW INSTITUTIONAL ECONOMICS: COMPLEMENTARY ASPECTS}

\begin{abstract}
The purpose of this article was to understand how the theoretical assumptions of the micro analytical level of New Institutional Economics (NIE), encompassing the Resource-Based View (RBV), the Transaction Cost Economics (TCE), and associated to the Economic Costs Measurement (ECM), might influence the choice of governance structures of companies. The method used was a literature review and descriptive research. Parallel to these theories, the RBV approach was chosen in order to discuss the relationship with the boundaries of the firm, and to identify the complementary aspects between these theoretical issues. The results showed that, when these approaches are considered together, it is evident that the possession and maintenance of strategic resources (VBR) characterizes property rights that need to be protected by legal mechanisms (ECT and ECM), able to minimize their loss of value, and secure property rights. Ultimately, the sustainability of a competitive advantage will be through structures that consider the presence of specific assets (ECT), measurability (ECM), and condition for competitiveness (VBR).
\end{abstract}

Keywords: Governance Structures; Transaction Cost Economics; Measurement Cost Economics; Resource Based View. 


\section{NUEVA ECONOMÍA INSTITUCIONAL: ASPECTOS COMPLEMENTARIOS}

\section{RESUMEN}

El objetivo de este artículo es entender cómo el microanalítico nivel teórico la Nueva Economía Institucional (NIE) supuestos, especialmente los que cubren economía de los costos de transacción (TCT) y Medida Economía Costo (ECM) asociada con la Visión Basada Recursos (VBR) pueden ser considerados en la comprensión de los límites de la empresa. A través de una búsqueda en la literatura, los resultados mostraron que al analizar conjuntamente estos enfoques, es claro que la propiedad y el mantenimiento de los recursos estratégicos (VBR) indican la necesidad de proteger sus derechos de propiedad a través de mecanismos legales (ECT y ECM ) que minimizar su pérdida de valor. Llegamos a la conclusión de que, en última instancia, a que sustentan las ventajas competitivas estarán a cargo de las estructuras de gobierno que tengan en cuenta la presencia de activos específicos (ECT), su capacidad de medición (ECM) y de su condición para la competitividad (VBR).

Palabras clave: Costo Economía Medición; Economía de los Costos de Transacción; Estructuras de Gobierno; Basada en Recursos View.

Cleiciele Albuquerque Augusto ${ }^{1}$ José Paulo Souza ${ }^{2}$ Silvio Antonio Ferraz Cario ${ }^{3}$

\footnotetext{
1 Doutoranda na Universidade Federal de Santa Catarina - UFSC. Brasil. E-mail: cleicielealbuquerque@yahoo.com.br
}

${ }^{2}$ Doutor em Engenharia de Produção pela Universidade Federal de Santa Catarina - UFSC. Professor no Departamento de Administração da Universidade Estadual de Maringá - UEM. Brasil. E-mail: jpsouza @uem.br

${ }^{3}$ Doutor em Ciência Econômica pela Universidade Estadual de Campinas - UNICAMP. Professor da Universidade Federal de Santa Catarina - UFSC. Brasil. E-mail: fecario@ yahoo.com.br 


\section{INTRODUÇÃO}

A discussão sobre instituições tem suas origens no velho institucionalismo, sobretudo com Thorstein Veblen (1857-1929), John R. Commons (1862-1945) e Wesley C. Mitchel (1874-1948), cujos trabalhos indicavam a importância das instituições na regulação do mercado e no desenvolvimento econômico de uma nação. Esses autores consideravam que a escola neoclássica não deu relativa importância ao papel das instituições e, com isso, propõem incluílas no centro de seu modelo analítico.

Tendo como base o trabalho desses autores, surgiram algumas abordagens institucionais com diferentes focos sobre a importância das instituições. Com o artigo de Ronald Coase, The Nature of the Firm, em 1937 e, a partir da década de 1970, com os trabalhos de Oliver Williamson $(1975,1985,1996)$ e Douglass North (1991), ganhou destaque a chamada Nova Economia Institucional (NEI), centrada na noção de custos de transação. Também diferente da abordagem neoclássica, cuja unidade de análise se foca na produção e nos custos de produção, a NEI, além de trazer para o centro de análise as instituições, apresenta, como unidade de análise, as transações e os custos delas originados.

Como destaca Williamson (2008), a NEI propõe duas vertentes analíticas complementares aplicáveis ao estudo das organizações. A primeira, de natureza macrodesenvolvimentista, focaliza a origem, estruturação e as mudanças das instituições ao longo do tempo. A segunda, conforme o autor, é de natureza microinstitucional e está preocupada com a análise de estruturas de governança, contemplando as microinstituições, ou seja, aquelas que regulam transações específicas. Entende-se, por meio da NEI, que as estruturas de governança consistem nas diversas formas que os agentes se utilizam para organizar suas transações, e podem ser classificadas em três tipos: integração vertical, formas híbridas (contratos) ou mercado livre, conforme especificado por Williamson (1985).

No nível microinstituicional, a NEI tem apresentado construções teóricas e explicativas de grande valor para o entendimento dos limites da firma, a partir da definição de estruturas de governança organizacionais. Essas construções tomam corpo na abordagem da Economia dos Custos de Transação (ECT) e da Economia dos Custos de Mensuração (ECM). Apresentando a transação como unidade de análise, essas abordagens apontam como objetivo básico reduzir os custos de transação, por meio de uma coordenação focada na eficiência.

Mais recentemente, alguns estudiosos têm buscado na Resourved Based View, ou Visão Baseada em Recursos (VBR), fundamentos teóricos sobre a configuração das estruturas de governança. A VBR indica que são os recursos e as capacidades diferenciadas que uma firma possui que lhes garantem a sustentação de vantagens competitivas. Sendo assim, conforme salientam Argyres e Zenger (2008), a lógica baseada em recursos tem sido estendida para além de uma referência nos estudos de estratégia, indicando méritos na explicação do desempenho das firmas e sustentação de vantagens competitivas, para explicações sobre sua configuração e seus limites. $\mathrm{Na}$ percepção de Jacobides e Winter (2005), economistas da Teoria da Firma agora aceitam que não podemos compreender inteiramente as escolhas de fronteiras sem avaliar as bases de recursos das empresas.

A NEI busca o alcance de vantagens competitivas a partir de uma gestão focada na eficiência, cuja minimização dos custos de transação se revela como aspecto principal na determinação da estrutura de governança apropriada. Pela ECT, os custos de transação são reduzidos na medida em que ocorre um alinhamento entre as estruturas de governança, os atributos de transação (especificidade de ativos, frequência e incerteza) e pressupostos comportamentais (racionalidade limitada e oportunismo) (Williamson, 1985). O principal fator diante do qual a estrutura de governança é escolhida, segundo Williamson (1991), é a especificidade de ativos, que pode se dar tanto em termos locacionais, físicos e humanos, quanto em termos de ativos dedicados, temporais e de marca. Já a ECM, proposta por Barzel (2005), implica na aceitação de que não só os atributos das transações poderiam explicar a escolha da estrutura de governança, mas, ainda, outras dimensões envolvendo a garantia de direito de propriedade e a condição de mensuração de dimensões transacionadas.

A VBR, por sua vez, parte do pressuposto de que a escolha da estrutura de governança ocorre a partir da capacidade superior que a firma pode demonstrar para desempenhar a atividade em relação às capacidades de fornecedores externos. Dito de outra forma, essa escolha é definida com base nos recursos estratégicos que a empresa possui, ou seja, em recursos valiosos e difíceis de serem imitados (Argyres; Zenger, 2008).

Seguindo essa linha de raciocínio, temos três construtos centrais que determinam a escolha pelas estruturas de governança a partir das abordagens teóricas apresentadas: ativos específicos, mensuráveis e recursos estratégicos. O objetivo é, simultaneamente, a redução de incertezas, a garantia de direito de propriedade e a obtenção de controle.

A tentativa de trabalhar os aspectos complementares dessas abordagens se traduz na realização de uma análise mais completa dos determinantes dos limites da firma. Estudos com tal propósito já foram observados na literatura da Teoria da Firma. Alguns deles se referem à integração da VBR com a ECT (Langlois, 1992; Williamson, 1999; Combs; Ketchen, 1999; Mahoney, 2001; Foss, 2005; Jacobides; Winter, 2005; Argyres; Zenger, 2008; Saes, 2009). Além disso, a VBR também tem sido associada 
Nova Economia Institucional: Vertentes Complementares

com a Análise de Posicionamento Estratégico - APE (Montgomery; Porter, 1998; Nickerson, 2003; Saes, 2009) e com a Teoria dos Lucros de Night - TLK (Nickerson; Zenger, 2004; Saes, 2009). A ECT, por sua vez, também tem sido discutida a partir de ligações com a ECM (Zylberzstajn, 2005). No entanto, ainda não se observam estudos que buscam discutir uma perspectiva conjunta da VBR com a ECT e ECM.

Vale justificar a importância de se trabalhar a complementaridade das teorias envolvidas, TCT, TCM e VBR, na tentativa de superar as limitações de cada teoria isolada, que enquadram a realidade dentro de construtos teóricos específicos e restringem a observação de outros aspectos, também presentes.

Corroborando esse ponto de vista, Silva (2009) e Breitenbach e Silva (2010) observam que existe na literatura uma crítica mais geral acerca da NEI, que não considera, ou até mesmo exclui, outros fatores também determinantes para os limites da firma. Ao analisar as principais críticas à TCT, Ferreira et. al. (2005, p. 2) também chamam atenção para os poucos trabalhos de caráter crítico envolvendo essa abordagem e para a "[...] necessidade de ampliar as diversas iniciativas já existentes, no sentido de estudar a possibilidade de integração da TCT com diversas teorias de diferentes campos do conhecimento".

Seguindo a mesma linha de raciocínio, Garcia e Bronzo (2000) destacam que a decisão da firma em produzir ou mandar fazer - o dilema mercado/hierarquia - presente na NEI, por um lado, depende não só da preocupação com os custos de transação, mas também de estratégias que buscam o aproveitamento de recursos e das competências distintivas. Por outro lado, ao se estudar a literatura sobre a VBR, percebe-se que grande parte dos estudos envolve a discussão dos benefícios de se obter recursos e capacidades que promovam vantagens competitivas, porém não são discutidos os mecanismos de coordenação envolvidos para sustentar essas vantagens competitivas. Ora, se a organização possui recursos que lhe garantem vantagem competitiva, a sustentação depende da criação de uma estrutura de governança que lhe permita controlar esses recursos e que pode ser auferida a partir dos princípios de coordenação presentes na TCT e TCM.

Diante do exposto, e a partir de uma pesquisa com abordagem qualitativa, do tipo descritiva e bibliográfica, este artigo tem como objetivo compreender como recursos estratégicos na VBR, ativos específicos na ECT e ativos mensuráveis pela ECM podem influenciar, em sua complementaridade, na escolha de estruturas de governança. Nesse sentido, busca-se descrever como essas teorias se complementam entre si na configuração de estruturas de governança. A ideia é abrir caminhos para explorar as relações entre essas abordagens teóricas, uma vez que os progressos obtidos nessa área deixam, ainda, grandes lacunas na compreensão de como os custos de transação, de mensuração e os recursos estratégicos se combinam para determinar os limites da firma.

\section{REFERENCIAL TEÓRICO}

Neste trabalho, objetiva-se compreender como ativos específicos, mensuráveis e recursos estratégicos podem influenciar a configuração das estruturas de governança e, consequentemente, os limites da firma. Para tanto, serão trabalhados três aportes teóricos: a ECT, a ECM e a VBR. A seguir, são apresentados alguns pressupostos básicos dessas abordagens, bem como suas perspectivas complementares.

\subsection{Nova economia institucional}

A Nova Economia Institucional tem suas origens no velho institucionalismo, sobretudo americano, com Veblen e Galbraith (Gomes, 2004). Conforme Farina et al. (1997), a NEI contempla aspectos da microeconomia tradicional ou clássica, abordando a teoria da firma com o propósito de identificar um mecanismo alternativo de coordenação das atividades econômicas, como também o mercado, suplantando a visão neoclássica onde a firma constituía unicamente uma função de produção.

Na visão de Sologuren e De Paula (2004), por meio desta nova abordagem, a integração vertical não é apenas entendida como uma forma de aumentar o poder de monopólio de mercado, como no chamado paradigma Estrutura-Conduta-Desempenho, mas passa a ser uma alternativa com vistas à minimização de custos de transação, podendo-se tornar um mecanismo de coordenação mais eficiente (ou não) do que o mercado. Para os autores, o instrumental analítico da NEI permitiu a compreensão das formas de organização das firmas e do ambiente institucional em que as transações são realizadas.

Desta forma, a unidade de análise da NEI são as transações e os custos delas originadas, contrastando com a visão neoclássica onde a unidade de análise é a produção e os custos de produção. Além disso, a NEI interpreta que a escola neoclássica não deu relativa importância ao papel das instituições e, com isso, propõe incluir as instituições no centro do modelo analítico (Gomes, 2004). Segundo North (2006), as instituições são as restrições humanas legadas que estruturam as interações políticas e sociais. Correspondem ao sistema de normas formais (constituição, leis, regulamentações), restrições informais (normas de conduta, costumes, convenções, tradições, tabus) e sistemas de controle que regulam a interação humana na sociedade. Para o autor, o ambiente institucional é definido pelo conjunto de regras políticas, sociais e legais que estabelecem as bases para a produção, troca e distribuição, também designadas como as regras do jogo social.

Sendo assim, a linha de argumentação da 
NEI discute o papel que as instituições exercem nas forças de mercado e, consequentemente, no processo de desenvolvimento econômico, focando a necessidade de regras bem estabelecidas para promover o seu funcionamento. Como salienta North (2006), a NEI possibilita uma visão mais ampliada do desempenho econômico ao trazer novos elementos de estudos, tais como custos de transação, incertezas, a coordenação das ações dos agentes econômicos, a assimetria informacional, a racionalidade limitada e o comportamento oportunista dos agentes, o direito de propriedade, a especificidade dos ativos, entre outros enfoques a ela inerentes.

Como esclarece Williamson (2008) e Zylbersztajn (2009), a NEI propõe duas vertentes analíticas complementares, aplicáveis ao estudo das organizações: uma macroanalítica e uma microanalítica. Na primeira, "[...] a questão central é explicar a origem e mudanças das instituições, vistas como as regras que pautam o comportamento da sociedade" (Zylbersztajn, 2009, p. 50). Nessa vertente, são abordadas algumas questões, tais como leis, normas, costumes e convenções, presentes no denominado ambiente institucional. Em tal grupo encontram-se os trabalhos de Douglas North, Steven Cheung e Barry Eichengreen, tendo como principal tema a relação entre as instituições e o desenvolvimento econômico.

A segunda vertente analítica, proposta pela NEI, de natureza microinstitucional, é representada pela economia das organizações, que estuda a natureza explicativa de diferentes estruturas de governança utilizadas pelas firmas na coordenação de suas transações. Nesse grupo, estão as contribuições de Harold Demsetz (UCLA), Oliver Williamson (TCT, University of California-Berkeley), Claude Menard (Paris I-Sorbonne), e Yoram Barzel (TCM, Washington University) e seu enfoque é microanalítico, ou seja, busca-se analisar as estruturas de governança utilizadas pelas organizações na realização de suas transações (Zylbersztajn, 2009).

Ambos os níveis analíticos se desenvolveram paralelamente, apresentando trajetórias distintas. No entanto, partiram de uma referência comum: o trabalho seminal de Coase (1937). A partir de Williamson (1991), a ligação entre ambiente institucional e estruturas de governança permitiu a composição de uma agenda de pesquisa comum, materializando-se na formalização da International Society of New Institutional Economics, em 1997. Na visão de Zylbersztajn (2009, p. 50), “[...] a operação das firmas vistas como arranjos institucionais é pautada pelas regras do jogo (instituições), o que confere a ligação entre as duas vertentes". Para o autor, ambas vertentes consideram as instituições relevantes e passíveis de análise.

Esta investigação apresenta um olhar sobre o segundo grupo, em que duas teorias apresentam destaque no tratamento de estruturas de governança utilizadas pelas firmas: a Economia dos Custos de
Transação e a Economia dos Custos de Mensuração. Os princípios básicos dessas teorias são apresentador a seguir.

\subsubsection{Economia dos custos de transação}

A TCT é uma das abordagens que compõem o nível microanalítico da NEI, apresentando como foco de análise o estudo sobre a formação de estruturas de governança organizacionais. Tem suas origens em 1937, no trabalho de Ronald Coase "The nature of the firm". Ao analisar as atividades de coordenação, Coase (1937) trouxe a noção de um novo tipo de custo além dos custos de produção, associados ao funcionamento dos mercados, mas não considerados pela teoria econômica até então: os custos de transação. Os custos de transação, segundo Barzel (2005, p. 359), “[...] são os custos de execução das transferências de direitos de propriedade e de proteção contra elas", sendo que os indivíduos optam por organizar as atividades de modo a dissipar a sua ocorrência. Para Zylbersztajn (2009), Coase introduziu uma mudança de paradigma na teoria econômica:

Basicamente Coase estava preocupado com as organizações do mundo real, como deixou claro no seu discurso ao receber o prêmio Nobel de Economia em 1991. Ao fazê-lo discutiu as razões explicativas para a existência da firma com base nos custos comparativos da organização interna e de produção via mercado, e lançou as bases para o estudo das formas alternativas de organização das firmas contratuais. Reconheceu que os mercados não funcionavam a custo zero, tampouco a organização interna da firma era desprovida de custos. (Zylbersztajn, 2009, p. 42).

Nas décadas de 1970 e 1980, especialmente a partir dos trabalhos realizados por Coase, Oliver Williamson impulsiona a questão dos custos de transação dentro da literatura econômica. A partir da visão da firma como um nexo de contratos, segundo Zylberztajn (2009, p. 43), esses autores abriram a possibilidade do "[...] estudo das organizações como 'arranjos institucionais' que regem as transações, seja por meio de contratos formais ou de acordos informais, os primeiros amparados pela lei, o segundo amparado por salva guardas reputacionais e outros mecanismos sociais". De acordo com Carvalheiro et al. (2004), as contribuições de Coase e Williamson são apontadas como de grande valia para a consolidação da Teoria dos Custos de Transação no debate acadêmico formal, e muitas de suas ideias ganharam contornos interdisciplinares.

Sendo assim, apresentando a transação como unidade de análise, a ECT tem como objetivo controlar os direitos de propriedade por intermédio de estruturas de governança apropriadas, que reduzam os custos de transação. Essas estruturas podem se dar via 
Nova Economia Institucional: Vertentes Complementares

mercado, contratos ou integração vertical, sendo definidas a partir dos atributos da transação e pressupostos comportamentais envolvidos.

Conforme destaca Williamson (1985), os atributos que caracterizam uma transação são três: a frequência, a incerteza e a especificidade de ativos, sendo este último o principal determinante da estrutura de governança a ser adotada. Segundo o autor, o atributo frequência diz respeito ao número de vezes que os agentes econômicos se encontram para realizar uma determinada transação. A incerteza, por sua vez, se apresenta a partir das mudanças que surgem da complexidade do ambiente econômico, impossibilitando a realização de avaliações totalmente precisas. Os ativos específicos, por sua vez, são ativos tangíveis ou intangíveis, irrecuperáveis, no sentido de que não podem ser reempregáveis em outra transação sem perda de valor, sendo eles: locacionais, temporais, físicos, dedicados, humanos e de marca (Williamson, 1985, 1996). Nesse sentido, quanto maior a frequência, a incerteza e a especificidade de ativos, maior a possibilidade de geração de custos de transação mais se tende a estrutura de governança via integração vertical.

Essa relação causal pode se estabelecer, segundo Williamson (1985) na presença de dois pressupostos comportamentais: o oportunismo e a racionalidade limitada. Em outras palavras, assume-se que os indivíduos são oportunistas e que há limites em sua capacidade cognitiva para processar a informação disponível. A consideração desses pressupostos distingue a ECT da abordagem tradicional com foco na produção e nos mercados.

A coordenação ocorre a partir da combinação das estruturas de governança com os atributos de transação e pressupostos comportamentais. $\mathrm{Na}$ estrutura de governança via mercado, conforme Williamson (1985), o nível de especificidade de ativos é baixo, logo, os custos de transação são mínimos, pois não há espaço para comportamentos oportunistas. Os agentes conhecem as características dos produtos transacionados, a incerteza e a frequência nas transações são mínimas e, normalmente, não se cria reputação entre os agentes. A integração vertical ou hierarquia, por sua vez, é motivada pelo alto nível de frequência, de incerteza e, principalmente, de especificidade de ativos, os quais geram possibilidades efetivas para geração de comportamento oportunista (Williamson, 1985, 1991).

Já os contratos ou formas híbridas, de acordo com Ménard (2004) e Zylbersztajn (2005), fogem dos custos das hierarquias e podem se fazer necessários para garantir que não haja captura da quase renda pelas partes envolvidas, ou seja, para garantir que não ocorra a perda ou expropriação do valor econômico do produto ou serviço transacionado. Em complemento à proposta de Williamson (1996), Ménard (2004) propõe que, entre os extremos do mercado e da hierarquia, a estrutura de governança contratual pode assumir diferentes configurações, constituindo arranjos menos formais até arranjos mais formais (Tabela 1).

Desdobrando a figura inicialmente desenvolvida por Williamson (1985) para explicar as decisões de formas alternativas de governança (mercado-contratos-hierarquia), Ménard (2004) desdobra a fronteira de eficiência dos contratos. Nesse sentido, busca destacar, de um menor para um maior nível de formalização, o papel das relações de confiança, redes relacionais, liderança e governança formalizada. A partir desse ponto, a hierarquia se mostra como a forma de governança mais apropriada na presença de alto nível de especificidade de ativos. $\mathrm{O}$ autor ainda salienta que, na medida em que as partes vão se conhecendo, a estrutura contratual é caracterizada pelo aumento do uso de mecanismos informais, tais como reputação, confiança, compartilhamento de informações e ajuda mútua, que são utilizados na coerção dos agentes.

Tabela 1 - Tipologia das organizações híbridas

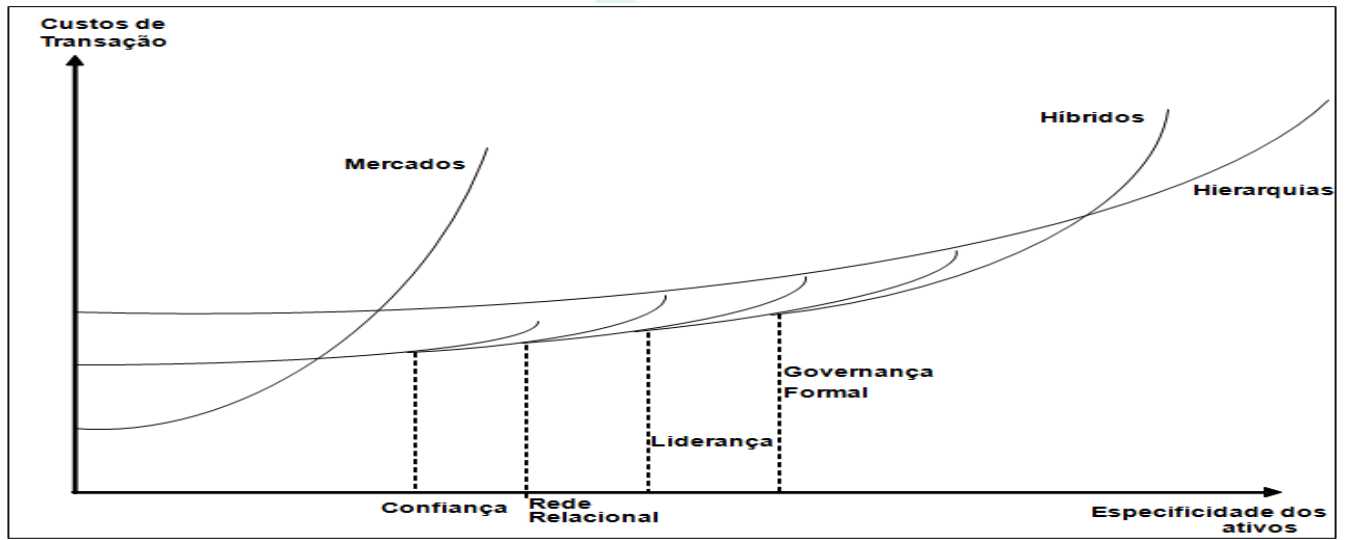

Fonte: Ménard (2004, p. 369) 
As estruturas de governança, conforme se pode observar, se definem sob um continuиm envolvendo incentivo e controle. Dessa forma, diferentes níveis de incentivo e controle são disponibilizados para a firma organizar suas atividades, em razão da escolha da estrutura de governança, conforme discutido em Williamson (1985) e depois tratado por Mizumoto e Zylbersztajn (2006, p. 150). Segundo os autores, “[...]arranjos via mercado são os que oferecem mais incentivos, mas a possibilidade de controle depende da existência de parceiros substitutos para disciplinar os desvios em relação ao acordo". Sendo assim, conforme a necessidade de controle aumenta, a firma passa a optar por arranjos contratuais em que é possível utilizar a ameaça de litígio para fazer cumprir o contrato. Nesse caso, a firma opta por arranjos hierarquizados em que as atividades são coordenadas internamente, ao preço de um incentivo menor vis-a-vis o arranjo via mercado.

\subsubsection{Economia dos custos de mensuração}

Embora Williamson ofereça explicação para a geração de eficiência, por meio do alinhamento de diferentes atributos de transação com estruturas de governança, a sua teoria de governança apresenta certo limite por tratar predominantemente com modos de governança polarizados (Zylbersztajn, 2005). A resposta para o melhor entendimento dessas formas alternativas de coordenação encontra solução ao se considerar a ECM, proposta por Yoran Barzel. Nessa perspectiva, não só os atributos das transações poderiam explicar as estruturas de governança, mas as dimensões envolvendo a garantia de propriedade e a condição de mensuração de ativos transacionados. A condição dessas variáveis justificaria a formação de arranjos estratégicos adequados à redução dos custos e maximização de valor nas transações.

Barzel (2005) observa que, sob diferentes condições, são estabelecidas distintas formas de acordos e de organização para resolver problemas relacionados aos custos de produção e de transmitir informações. Para o autor, a mensuração é uma particular forma de informação e necessária no processo de troca. A troca, por sua vez, deve ser governada por variadas formas de "enforcement", sendo que Barzel destaca os acordos de longo prazo, as relações contratuais garantidas pelo estado, os leilões e, também, aquelas ocorridas dentro das organizações, com efeitos em nível horizontal e vertical.

Como a ECT, o modelo de Barzel se adéqua ao objetivo de redução dos custos de transações, seguindo o modelo proposto por Coase (1937), entretanto, difere do ECT em termos de unidade de análise e pressupostos, além de não apresentar o impacto empírico equivalente. Além disso, o custo de transação para Barzel (2003, p. 52, tradução nossa), ao considerar a informação incompleta e equivalente possibilidades de captura de valor, é definido como:
“[...] recursos utilizados para estabelecer e manter direitos econômicos". O autor complementa: "Essa definição é consistente com o teorema de Coase. Se os custos de transação são zero, então direitos de propriedade são perfeitamente estabelecidos". Monteiro e Zylbersztajn (2011, p. 106) ao tratar dos custos de transação, na proposição de Barzel, concluem que esses envolvem: "[...] custo associados ao esforço de um agente em garantir seu direito econômico de propriedade quando determinados atributos escapam para o domínio público".

Zylbersztajn (2005) identifica os seguintes aspectos que configuram a ECM para a análise empírica: a decomposição das transações em dimensões a serem mensuradas, como unidade de análise; o oportunismo implícito, a racionalidade limitada e a impossibilidade de mensuração em contratos, como concepção; a dificuldade de mensurar, determinando a integração vertical e horizontal, como pressuposto; a organização interna resultante da perspectiva da maximização do valor em qualquer momento no tempo. Além disso, o autor observa que na ECM um conjunto de direitos econômicos e legais são trocados, sendo os primeiros garantidos privadamente e os últimos, pelo estado.

Nessa consideração, assim como os benefícios não são os mesmos, a complexidade, dada a decomposição nas dimensões transacionadas e as estruturas de cooperação adotadas, identifica que as relações podem ser coordenadas por contratos formais (direito legal) e acordos informais (direito econômico) e seus respectivos mecanismos de garantias (enforcement). "Acordos envolvem relacionamentos completos. Contratos são acordos ou parte de acordos garantidos pelo estado" (Barzel, 2001, p. 9, tradução nossa). Conforme Zylbersztajn (2005, p. 16, tradução nossa): "Espera-se que contratos formais e acordos informais governem dimensões particulares de uma dada transação [...] sugerindo que a governança deva ser considerada como mecanismo designado para minimizar a dispersão de valor das múltiplas dimensões de uma única transação". Os custos de transação emergem, nesse caso, como os recursos que são utilizados para estabelecer e manter direitos econômicos. Se os custos de transação são zero, significa que os direitos de propriedade são perfeitamente estabelecidos e mantidos.

Para o autor, o aspecto chave dos custos de transação está na mensurabilidade dos atributos dos bens. Tal mensuração pressupõe avaliar não só as dimensões físicas dos atributos do objeto de troca (cor, tamanho, peso, quantidade, entre outros), como também as dimensões dos direitos de propriedade incluídos na troca. Barzel (2003) constata que a mensuração tem um custo e, em certas situações, o mercado pode ser a instituição mais cara para organizar a produção do que a firma. Sendo assim, a empresa integraria verticalmente quando a dificuldade de se mensurar as mercadorias envolvidas na troca ou de se 
definir os direitos de propriedade transacionados resultasse em custos de transação elevados.

Dessa forma, como na ECT, a busca pela redução dos recursos associados à captura oportunista aponta a integração vertical e os contratos de longo prazo como alternativas factíveis, além da padronização de ativos idiossincráticos como meio para evitar a disputa. Nesse caso, de acordo com Barzel (2005), o uso da padronização evita o incentivo para captura oportunista, embora possa envolver perdas pela redução da variedade. Já a integração vertical é atrativa quando processadores a jusante desejam garantir seus produtos por meio dos agentes a montante com possibilidade de ganhos oportunistas. Para o autor, o uso de contratos de longo prazo parece ser especialmente eficaz, em situações em que os agentes transacionam diretamente entre si, dado que a reputação entre as partes pode ser construída.

Em complemento à proposta de Williamson (1985), a ECM trata dos limites da firma ou da estrutura de governança na perspectiva da busca pela proteção de direito de propriedade. Nesse caso, a integração vertical se justificaria quando, na presença de ativo de elevada especificidade, não fosse assegurada a garantia do direito legal da propriedade devido a dificuldade de mensuração. Esse aspecto estabelece relevante contribuição ao estudo das organizações, dada à consideração da relação contratual como forma de garantia de controle, à luz dos pressupostos envolvendo o direito de propriedade nas transações.

\subsection{Visão baseada em recursos}

A Visão Baseada em Recursos (do inglês, Resource Based View - RBV) tem sua origem na teoria econômica, especialmente a partir dos estudos de Penrose (1959), que defende que as empresas desenvolvem suas vantagens competitivas por meio das imperfeições do mercado. As singularidades advindas destas imperfeições provêem a base para o desenvolvimento de novos produtos e, simultaneamente, de capacidades ou recursos únicos. Nessa concepção, como explica Saes (2009), a vantagem competitiva estaria na empresa que tem os recursos difíceis de imitar, ou seja, na habilidade da empresa de encontrar ou criar recursos e capacidades que são verdadeiramente distintivos, aqui denominados recursos estratégicos.

Apesar da constatação de Penrose, esses recursos só passaram a ser considerados de forma efetiva pela VBR a partir do trabalho de Wernefelt (1984), em que foi estabelecido um paralelo entre a Visão Tradicional Baseada em Produtos, defendida pelo modelo competitivo de Porter (1985), e a Visão Baseada em Recursos. Segundo Wernefelt, as ideias sobre a VBR só se tornaram relevantes a partir de 1990, quando Prahalad e Hamel popularizaram sua visão a respeito de capacidades dinâmicas (Mintzberg, et al, 2000).

Barney (1991) vem ao encontro dos argumentos de Wernefelt e amplia a perspectiva original de Penrose, afirmando que o conjunto de recursos da firma não é somente uma lista de fatores, mas o processo de interação entre esses recursos e os seus efeitos sobre a organização. Na visão de Barney (1991), para serem estratégicos, os recursos devem ser valiosos, raros, imperfeitamente imitáveis e insubstituíveis, de modo a possibilitar que a empresa crie e siga estratégias eficazes. Eles podem ser classificados como recursos de capital físico (tecnologia, fábrica, equipamentos, localização geográfica, acesso a matérias-primas), recursos de capital humano (treinamento, experiência, inteligência, relacionamentos) e recursos de capital organizacional (sistemas e estruturas formais, bem como relações informais entre grupos).

Após Barney (1991), Peteraf examina as condições dos recursos que asseguram as vantagens competitivas sustentáveis, em seu artigo The cornerstones of competitive advantage, publicado em 1993. Na visão da autora, os recursos rendem uma vantagem competitiva sustentável para a empresa quando apresentam: superioridade, no sentido de serem heterogêneos, para garantir a obtenção de lucros diferenciais; barreiras ex-post à competição, ou seja, são difíceis de imitar devido aos mecanismos de isolamento presentes; barreiras ex-ante à competição, em que assimetrias de informação são necessárias para limitar a competição explícita pelos recursos; imobilidade, quando possuírem especialização ou especificidade que os tornam adaptados exclusivamente para suas necessidades.

Tendo como base a presença de recursos e capacidades diferenciadas, a VBR indica que as vantagens competitivas são provenientes de atividades ocorrendo nas rotinas, nos processos, nas posições e nos caminhos da empresa, os seus path dependencies (Teece; Pisano, Shuen, 1997). Em outras palavras, a vantagem competitiva é proveniente da memória, do aprendizado e dos caminhos trilhados pela organizacão ao longo do tempo. Com isso, de acordo com Saes (2009), as escolhas estratégicas a serem feitas pelos tomadores de decisão dentro da empresa implicam na escolha de caminhos de longo prazo, sendo um processo difícil e caro porque envolve a construção de recursos que não podem ser comprados.

Além dos path dependencies, outro pressuposto básico da VBR é a heterogeneidade das firmas. Conforme observa Kohls e Fensterseifer (2004, p. 3), para a VBR não existem duas empresas (exatamente) iguais, “[...] pois não há duas empresas com o mesmo conjunto de experiências, ativos, habilidades e culturas organizacionais. Com base nessa premissa, a empresa disporá de condições para ser bem sucedida se tiver um adequado estoque de recursos para a sua estratégia de negócio". Dessa forma, o pressuposto fundamental da VBR é que as 
organizações são, essencialmente, diferentes conjuntos de recursos que conduzem a diferentes capacidades competitivas.

Outro aspecto da VBR é que a fonte de vantagem competitiva se dá por meio da captação de rendas por meio de vantagens de eficiência, as denominadas rendas ricardianas. Segundo Saes (2009), essas rendas surgem em razão do acesso da empresa a recursos que as suas concorrentes não têm. São rendas derivadas da escassez diante da demanda e provenientes de fatores valorizados, mas inerentemente

\section{COMPLEMENTARIDADES DAS TRESS ABORDAGENS}

A tentativa de trabalhar aspectos complementares entre abordagens na área de estratégia, buscando uma visão capaz de compreender de forma mais completa a explicação das fontes de vantagem competitiva da firma e minimizar suas limitações individuais, é recente. De acordo com Saes (2009), esse momento de integração entre diferentes abordagens de estratégia surgiu a partir dos anos 1990, mas já conta com várias iniciativas.

Nessas iniciativas, essa seção tem como objetivo trabalhar os aspectos complementares das abordagens indicadas. Para tanto, em um primeiro momento, será realizada análise comparativa entre a ECT e ECM, tendo como aspectos de análise: (a) origem, (b) raros e difíceis de obter.

Nota-se que diversos estudiosos têm focado seu trabalho na descrição dos recursos e nas capacidades estratégicas inerentes ao ambiente interno das organizações. Ainda que diversos progressos tenham sido alcançados, desde os pensadores clássicos como Penrose (1959), Wernefelt (1984), Barney (1991) e Peteraf (1993), com seu foco nas relações intraorganizacionais, evidencia-se a necessidade da continuidade dos estudos na área, dadas as limitações ainda discutidas para aplicação empírica do modelo.

unidade de análise, (c) pressupostos, (d) hipóteses testáveis, (e) processos, (f) racional. Na sequência, serão presentados alguns aspectos complementares entre a ECT e a VBR, utilizando os mesmos aspectos de análise. Por fim, as três teorias são analisadas em sua complementaridade, a partir da estrutura composta nas análises anteriores.

\subsection{Aspectos em análise}

A estrutura de análise básica das três abordagens é inspirada no trabalho de Zylbersztajn (2005). Ao realizar uma análise comparativa entre a ECT e a ECM, Zylbersztajn (2005) contrasta os seus pressupostos básicos, a saber os custos de transação e mensuração, trazendo informações relevantes para a construção teórica deste trabalho (Tabela 2).

Tabela 2 - Contrastes - Paradigmas da ECT e ECM.

\begin{tabular}{|c|c|c|c|}
\hline & ECT & ECM & COMENTÁRIOS \\
\hline Origem & $\begin{array}{l}\text { Importância das } \\
\text { instituições. }\end{array}$ & Importância das instituições. & $\begin{array}{l}\text { A proteção dos direitos de } \\
\text { propriedade é relevante em } \\
\text { ambas as abordagens. }\end{array}$ \\
\hline $\begin{array}{l}\text { Unidade de } \\
\text { análise }\end{array}$ & $\begin{array}{l}\text { Transação: resultante das } \\
\text { características de } \\
\text { frequência, especificidade } \\
\text { de ativos e incerteza. }\end{array}$ & $\begin{array}{l}\text { Transação: decomposta em } \\
\text { dimensões. } \\
\text { Um conjunto de direitos } \\
\text { econômicos e legais são } \\
\text { trocados e garantidos pelo } \\
\text { Estado ou privadamente. }\end{array}$ & $\begin{array}{l}\text { Na visão de governança, as } \\
\text { características das transações } \\
\text { facilitam a análise empírica. } \mathrm{Na} \\
\text { ECM, cada dimensão carrega } \\
\text { um nível de dificuldade de } \\
\text { medição. }\end{array}$ \\
\hline Pressupostos & $\begin{array}{l}\text { Oportunismo } \\
\text { Contratos incompletos } \\
\text { provenientes de mudanças } \\
\text { ex-post do estado de } \\
\text { natureza e da } \\
\text { racionalidade limitada. }\end{array}$ & $\begin{array}{l}\text { Oportunismo implícito. } \\
\text { Racionalidade limitada. } \\
\text { Contratos incompletos, a } \\
\text { medição perfeita é impossível. }\end{array}$ & $\begin{array}{l}\text { Na perspectiva da governança, } \\
\text { os contratos incompletos se } \\
\text { relacionam ao oportunismo. } \\
\text { Na ECM, a maximização leva } \\
\text { aos custos de mensuração. }\end{array}$ \\
\hline $\begin{array}{l}\text { Hipótese } \\
\text { testável }\end{array}$ & $\begin{array}{l}\text { Maior nível de } \\
\text { especificidade de ativos } \\
\text { implica numa maior } \\
\text { integração vertical ou } \\
\text { contratos de longo prazo. }\end{array}$ & $\begin{array}{l}\text { Dificuldade para medir } \\
\text { atributos dentro da empresa. } \\
\text { Direitos de propriedade são } \\
\text { colocados com quem oferece } \\
\text { garantias. }\end{array}$ & $\begin{array}{l}\text { Ambos têm implicações } \\
\text { dinâmicas. } \\
\text { Transformações fundamentais e } \\
\text { mudanças nos custos de } \\
\text { mensuração. }\end{array}$ \\
\hline $\begin{array}{l}\text { Processo } \\
\text { principal }\end{array}$ & $\begin{array}{l}\text { Características das } \\
\text { transações determinam a } \\
\text { estrutura de governança }\end{array}$ & $\begin{array}{l}\text { Dificuldade de mensuração } \\
\text { determina a interação vertical e } \\
\text { horizontal, bem como a } \\
\text { estrutura interna da firma. }\end{array}$ & $\begin{array}{l}\text { ECM prevê a complexa } \\
\text { estrutura interna de transações. }\end{array}$ \\
\hline
\end{tabular}




\begin{tabular}{|c|c|c|c|}
\hline $\begin{array}{c}\text { Organização } \\
\text { segue o } \\
\text { racional }\end{array}$ & $\begin{array}{l}\text { Estrutura de governança } \\
\text { resulta da perspectiva de } \\
\text { alinhamento com os } \\
\text { atributos de transação e } \\
\text { pressupostos } \\
\text { comportamentais. } \\
\text { Minimização de custos de } \\
\text { transação. } \\
\text { Decisão é tomada ex-ante, } \\
\text { considerando os riscos ex- } \\
\text { post. }\end{array}$ & $\begin{array}{l}\text { Resultados da estrutura } \\
\text { organizacional interna a partir } \\
\text { da perspectiva de maximização } \\
\text { de valor. } \\
\text { Decisão é tomada a qualquer } \\
\text { momento }\end{array}$ & $\begin{array}{l}\text { ECM não explora elementos } \\
\text { intertemporais. }\end{array}$ \\
\hline
\end{tabular}

Fonte: Zylbersztajn (2005)

Para o autor, ambas as teorias têm suas origens a partir da constatação da importância das instituições, que são tomadas como dadas, visando proteger os direitos de propriedade das partes envolvidas na transação. Em termos de unidade de análise, tanto a ECT quanto a ECM adotam a transação, levando-se em conta, respectivamente, os atributos de transação e as dificuldades de mensuração para a escolha da estrutura de governança.

Em se tratando de pressupostos, a ECT e a ECM são caracterizadas pelo comportamento oportunista, pela racionalidade limitada e pelos direitos de propriedade maldefinidos. No entanto, enquanto na ECT os contratos incompletos são mais relacionados à mudança ex-post, ao oportunismo e à racionalidade limitada, na ECM eles resultam da medição imperfeita dos recursos transacionados. Além disso, ao passo em que a ECT parte da perspectiva de minimizar os custos de transação a partir de decisões tomadas ex ante, considerando os riscos ex post, a ECM busca maximizar valor, sendo que a decisão é tomada a qualquer momento, ou seja, a abordagem não explora elementos intertemporais.

Quanto às hipóteses testáveis, na perspectiva da ECT, considera-se que a integração vertical é esperada quanto maior for o nível de especificidade de ativos envolvidos. A inserção da especificidade, associada aos demais atributos, permite que diferentes mecanismos pós-contratuais, com distintos níveis de coordenação, sejam construídos para lidar com as incertezas. Além disso, a inclusão de mecanismos reputacionais, resultantes da frequência identificada na transação, é relevante. Em contrapartida, a ECM oferece contribuição efetiva na análise empírica das formas híbridas. Como hipótese, define que a propriedade de um ativo está com aquele que pode oferecer garantias e, nesse sentido, se o estado pode garantir direitos de propriedade, então, os agentes são mais propensos a contratação do que à propriedade desse ativo. Assim, a facilidade em medir esses atributos facilitaria a transação fora da firma, dado que a mensuração seria fácil e as disputas no âmbito legal facilmente resolvidas.

Essas hipóteses definem os processos a serem seguidos. Se, por um lado, na ECT, o maior nível de especificidade de ativo resulta em maior incerteza nos resultados e define ganhos a partir da coordenação, sendo a integração vertical mais observada, por outro, a ECM propõe que, se o atributo apresenta variabilidade na sua medição, maior é a dificuldade de predição nos resultados, o que implica em maior dificuldade de contratação. Essa situação pode levar, também, a propriedade do ativo ou integração vertical, como forma de minimizar a possibilidade de dissipação de valor. Esse racional indica que a coordenação, pela ECT, é resultante da busca do alinhamento entre as estruturas de governança, os atributos das transações, especialmente a especificidade de ativos, e dos comportamentos dos agentes.

$\mathrm{Na}$ ECM, busca-se garantir que os ganhos inerentes às margens dos atributos do produto não sejam dissipados, sendo que a integração vertical é incentivada quando a mensuração é difícil e os direitos de propriedade não são claramente definidos.

De acordo com o quadro definido por Zylbersztajn (2005) e com referencial teórico utilizado, é possível destacar alguns aspectos complementares na Tabela 3, em se tratando especificamente da ECT e da VBR. Enquanto a origem da ECT está vinculada à importância das instituições, como destacado pelo autor, a da VBR se relaciona com a competição em mercados imperfeitos, o que possibilita o desenvolvimento de recursos e capacidades únicas a partir de oportunidades vislumbradas (Penrose, 1959). O aspecto complementar está na questão de que são as instituições, cuja importância é investigada pela ECT, que garantem a proteção dos direitos de propriedade dos recursos e das capacidades, analisados pela VBR. Dito de outra forma, são as microinstituições, na forma de estruturas de governança, que podem garantir a proteção da propriedade dos recursos e das capacidades envolvidas nas transações interfirmas. 
Tabela 3 - Aspectos complementares envolvendo a ECT e VBR

\begin{tabular}{|c|c|c|c|}
\hline & ECT & VBR & $\begin{array}{c}\text { COMPLEMENTARIDADE ECT } \\
\text { E RBV }\end{array}$ \\
\hline Origem & Importância das Instituições. & $\begin{array}{l}\text { Competição em mercados } \\
\text { imperfeitos (Penrose, 1959). }\end{array}$ & $\begin{array}{l}\text { Instituições estabelecem as regras } \\
\text { do jogo e garantem o direito de } \\
\text { propriedade dos recursos e das } \\
\text { capacidades. }\end{array}$ \\
\hline $\begin{array}{l}\text { Unidade de } \\
\text { análise }\end{array}$ & $\begin{array}{l}\text { Transação: resultante das } \\
\text { características de frequência, } \\
\text { especificidade de ativos e } \\
\text { incerteza }\end{array}$ & $\begin{array}{l}\text { Estratégia (Barney, 1991). } \\
\text { Recursos (Peteraf, 1993). }\end{array}$ & $\begin{array}{l}\text { Proteger recursos estratégicos } \\
\text { superiores demanda custos de } \\
\text { transação. }\end{array}$ \\
\hline Pressupostos & $\begin{array}{l}\text { Oportunismo } \\
\text { Contratos incompletos } \\
\text { provenientes de mudanças ex- } \\
\text { post do estado de natureza e da } \\
\text { racionalidade limitada. }\end{array}$ & $\begin{array}{l}\text { Vantagem competitiva } \\
\text { sustentável amparada por } \\
\text { recursos e capacidades. } \\
\text { A integração vertical protege as } \\
\text { condições superiores de } \\
\text { concorrência. }\end{array}$ & $\begin{array}{l}\text { Mecanismos de proteção de } \\
\text { recursos, capacidades e atributos, } \\
\text { exigem estruturas de governança } \\
\text { apropriadas. }\end{array}$ \\
\hline $\begin{array}{l}\text { Hipótese } \\
\text { testável }\end{array}$ & $\begin{array}{l}\text { Maior nível de especificidade } \\
\text { de ativos implica em uma maior } \\
\text { integração vertical ou contratos } \\
\text { de longo prazo. }\end{array}$ & $\begin{array}{l}\text { Alto nível de recursos não } \\
\text { imitáveis demanda integração } \\
\text { vertical. }\end{array}$ & $\begin{array}{l}\text { Hierarquia como alternativa para } \\
\text { proteção e controle de ativos } \\
\text { específicos ou recursos estratégicos. }\end{array}$ \\
\hline $\begin{array}{l}\text { Processo } \\
\text { principal }\end{array}$ & $\begin{array}{l}\text { Características das transações } \\
\text { determinam a estrutura de } \\
\text { governança. }\end{array}$ & $\begin{array}{l}\text { Capacidades e recursos } \\
\text { determinam a estrutura de } \\
\text { governança. }\end{array}$ & $\begin{array}{l}\text { Construção de capacidades e } \\
\text { recursos distintos no tempo } \\
\text { caracteriza direitos de propriedade } \\
\text { que necessitam ser protegidos pela } \\
\text { integração vertical. }\end{array}$ \\
\hline $\begin{array}{l}\text { Organização } \\
\text { segue o } \\
\text { racional }\end{array}$ & $\begin{array}{l}\text { Estrutura de governança resulta } \\
\text { da perspectiva de alinhamento } \\
\text { com os atributos de transação e } \\
\text { pressupostos comportamentais. } \\
\text { Minimização de custos de } \\
\text { transação. Decisão é tomada ex- } \\
\text { ante, considerando os riscos } e x \text { - } \\
\text { post. }\end{array}$ & $\begin{array}{l}\text { Capacidades e recursos devem } \\
\text { ser mantidos e controlados. } \\
\text { Garantias de direito de } \\
\text { propriedade são necessárias } \\
\text { para explorar oportunidades. } \\
\text { Decisão é tomada } \text { ex ante para } \\
\text { gerar recursos e capacidades } \\
\text { superiores ex-post. }\end{array}$ & $\begin{array}{l}\text { Recursos e capacidades completam } \\
\text { os atributos que justificam as } \\
\text { estruturas de governança } \\
\text { necessárias à construçâo de } \\
\text { vantagens competitivas duradouras. } \\
\text { Decisões ex-ante identificam } \\
\text { estratégias de sucesso sustentáveis } \\
\text { ex-post. }\end{array}$ \\
\hline
\end{tabular}

Fonte: Elaborado pelos autores, a partir de Zylbersztajn (2005)

No que se refere à unidade de análise, a complementaridade das abordagens se encontra na consideração de que capturar e proteger recursos estratégicos superiores, pela VBR, demanda custos de transação, focados pela ECT. Em termos de pressupostos, destaca-se que a proteção dos recursos e das capacidades, tratados pela VBR, demandam custos de transação e exigem mecanismos de controle e estruturas de governança apropriadas, discutidas pela ECT.

Ressalta-se ainda, como hipótese testável, que tanto a especificidade de ativos, como atributo de transação na ECT, quanto os recursos estratégicos, como unidade de análise na VBR, demandam estruturas integradas verticalmente, visando maior controle por parte da empresa dos ativos demandados. $\mathrm{O}$ processo principal denota outro aspecto complementar ao evidenciar que não somente os atributos das transações, como também os recursos e as capacidades disponíveis na empresa, determinam a escolha da estrutura de governança, sendo que quando se tratam de recursos estratégicos, faz-se necessário proteger os seus direitos de propriedade a partir da integração vertical. Por fim, o racional pressupõe que recursos e capacidades completam os atributos de transação que justificam as estruturas de governança necessárias à construção de vantagens competitivas duradouras. Nesse sentido, decisões ex- ante identificam estratégias de sucesso sustentáveis ex-post.

Alguns outros autores têm destacado aspectos complementares envolvendo a ECT e a VBR. Langlois (1992, p. 99) afirma que "[...] em conjunto com os custos de governança, as capacidades da empresa e do mercado determinam os limites da firma no curto prazo". Sendo assim, as considerações da VBR caminham lado a lado com as considerações da ECT. Seguindo essa linha de raciocínio, Poppo e Zenger (1998) e Argyres e Zenger (2008) defendem que a integração vertical pode ocorrer não apenas pela presença de ativos específicos ou oportunismo, como prega a ECT, mas pelo fato da organização, por si mesma, apresentar características vantajosas como 
opção de governança. Nessa perspectiva, Ghoshal e Moran (1996, p. 42, tradução nossa) destacam que as vantagens das organizações sobre os mercados, além de serem definidas por custos de transação, podem estar relacionadas a tentativa de explorar os propósitos internos da organização e a sua diversidade, ou seja, "[...] alavancar a habilidade humana da organização para tomar a iniciativa, para cooperar e para aprender". Ademais, segundo Langlois (1992), Argyres e Zenger (2008) e Saes (2009), a VBR suporta a escolha de estruturas de governança (ECT), uma vez que as mudanças nessas estruturas dependem de um processo de realimentação, pelo aprendizado e uso de experiências pessoais dos gerentes sobre os custos de transação envolvidos. Por outro lado, a ECT explica quais estruturas de governança são mais eficientes para explorar os recursos estratégicos da firma. Em consonância, Combs e Ketchen (1999) avaliam que, enquanto a VBR busca a identificação de recursos estratégicos que exigem melhorias, a ECT incide sobre a forma de gerir esses recursos depois de identificados.

Outro ponto de complementaridade está relacionado à especificidade de ativos. Isto porque, os recursos estratégicos da firma (VBR) podem ser interpretados como ativos específicos e, assim, analisados a partir do instrumental da ECT. Combs e Ketchen (1999) ressaltam que a visão das abordagens é complementar, em parte, devido ao reconhecimento de que ativos específicos compartilham uma qualidade importante com os recursos estratégicos, ou seja, ambos são difíceis de comercializar ou imitar. Segundo os autores, essa complementaridade esclarece porque o alto desempenho entre as empresas pode ser explicado tanto como um produto da gestão organizacional focada na eficiência (ECT), quanto da exploração de recursos estratégicos (VBR).

Embora sejam observados alguns avanços na discussão envolvendo a complementaridade entre ECT e VBR, estudos envolvendo a integração dessas teorias com a ECM ainda não são observados. Conforme visualizado, foram contrastados pressupostos da ECT e ECM, bem como destacados alguns aspectos complementares da ECT com a VBR. A partir desses argumentos, na Figura 4, são sugeridos alguns pressupostos quanto a complementaridade dos três enfoques discutidos: a VBR, a ECT e a ECM, conjuntamente. Considera-se que, individualmente, a ECT e a ECM estão relacionadas, respectivamente, a possibilidade de redução de custos de transação e de garantia de direito de propriedade em dimensões mensuráveis, sendo a VBR preocupada com a identificação e exploração de recursos e capacidades estratégicos para a organização.

\subsection{Propostas de complementaridade para as três teorias}

Retomando a estrutura proposta anteriormente, vale destacar que enquanto a ECT e a ECM têm sua origem justificada na importância das instituições, a VBR parte do pressuposto de que recursos estratégicos podem surgir a partir da competição em mercados imperfeitos. Nesse caso, observa-se que um aspecto complementar entre os três aportes teóricos se encontra no argumento de que as instituições, cuja importância é determinante para a ECT e ECM, estabelecem as regras do jogo e garantem direito de propriedade dos recursos estratégicos, tratados pela VBR, em ambientes competitivos. Nesse raciocínio, enquanto a ECT e a ECM focam, como unidade de análise, a transação, a VBR ainda não é consensual quanto a sua unidade de análise, sendo considerada a estratégia, por Barney (1991) e os recursos, por Peteraf (1993). Nesse ponto, a complementaridade das abordagens encontra-se no argumento de que proteger recursos estratégicos pode gerar custos de transação e custos de mensuração, demandando estruturas de governança específicas.

Outro aspecto comum das abordagens é visualizado em termos de pressuposto teórico. Enquanto a ECT considera que contratos completos são impossíveis devido a incerteza e a racionalidade limitadas dos agentes, a ECM parte do principio de que a incompletude contratual ocorre devido a impossibilidade de se realizar medidas exatas. Pela VBR, como recursos estratégicos geram a vantagem competitiva da organização e, portanto, a sua continuidade no mercado, a integração vertical se faz necessária devido a necessidade de controle requisitada para a proteção desses recursos. Com isso, a complementaridade encontra-se na constatação de que recursos específicos (ECT), difíceis de serem mensurados (ECM) e estratégicos (VBR) podem aumentar a possibilidade de perda de valor, oportunismo e contratos incompletos, e podem demandar estruturas mais integradas verticalmente.

O processo principal indica, portanto, que, enquanto pela ECT as características da transação determinam a escolha de estruturas de governança, pela ECM, essa escolha é realizada devido a dificuldades decorrentes da mensuração. Pela VBR, a escolha se dará em função da necessidade de proteger recursos estratégicos. Com isso, uma perspectiva complementar pressupõe-se que os atributos de transação, a condição do recurso estratégico e a sua mensurabilidade determinam a estrutura de governança mais adequada para proteger e sustentar vantagem competitiva. $\mathrm{O}$ racional sugere que a proteção e sustentação de vantagens competitivas se dará por meio de estruturas de governança que levem em consideração o seu alinhamento com atributos de transação e pressupostos comportamentais (ECT), a mensurabilidade dos ativos específicos envolvidos e a sua condição de competitividade. Esses argumentos são esboçados na Tabela 4, apresentado a seguir. 
Tabela 4 - Aspectos complementares envolvendo a VBR, ECT e ECM.

\begin{tabular}{|c|c|c|c|c|}
\hline & ECT & ECM & VBR & $\begin{array}{c}\text { PRESSUPOSTOS QUANTO À } \\
\text { COMPLEMENTARIDADE } \\
\text { ECT, ECM E VBR }\end{array}$ \\
\hline Origem & $\begin{array}{l}\text { Importância das } \\
\text { instituições. }\end{array}$ & $\begin{array}{l}\text { Importância das } \\
\text { instituições. }\end{array}$ & $\begin{array}{l}\text { Competição em } \\
\text { mercados imperfeitos } \\
\text { (Penrose, 1959). }\end{array}$ & $\begin{array}{l}\text { Instituições estabelecem as regras do } \\
\text { jogo e garantem direito de propriedade } \\
\text { dos recursos e das capacidades em } \\
\text { ambientes de competição. }\end{array}$ \\
\hline $\begin{array}{l}\text { Unidade } \\
\text { de análise }\end{array}$ & $\begin{array}{l}\text { Transação: resultante } \\
\text { das características de } \\
\text { frequência, } \\
\text { especificidade de ativos } \\
\text { e incerteza. }\end{array}$ & $\begin{array}{l}\text { Transação: } \\
\text { decomposta em } \\
\text { dimensões. } \\
\text { Um conjunto de } \\
\text { direitos econômicos } \\
\text { e legais são trocados } \\
\text { e garantidos pelo } \\
\text { Estado ou } \\
\text { privadamente. }\end{array}$ & $\begin{array}{l}\text { Estratégia (Barney, } \\
\text { 1991). } \\
\text { Recursos (Peteraf, } \\
\text { 1993). }\end{array}$ & $\begin{array}{l}\text { Proteger recursos superiores demanda } \\
\text { custos de transação e custos de } \\
\text { mensuração, exigindo estruturas de } \\
\text { governança específicas. }\end{array}$ \\
\hline $\begin{array}{l}\text { Pressu- } \\
\text { postos } \\
\text { teóricos }\end{array}$ & $\begin{array}{l}\text { Oportunismo } \\
\text { Contratos incompletos } \\
\text { provenientes de } \\
\text { mudanças ex-post do } \\
\text { estado de natureza e da } \\
\text { racionalidade limitada. }\end{array}$ & $\begin{array}{l}\text { Oportunismo } \\
\text { implícito. } \\
\text { Racionalidade } \\
\text { limitada. } \\
\text { Contratos } \\
\text { incompletos, a } \\
\text { medição perfeita é } \\
\text { impossível. }\end{array}$ & $\begin{array}{l}\text { Vantagem } \\
\text { competitiva } \\
\text { sustentável amparada } \\
\text { por recursos e } \\
\text { capacidades. } \\
\text { A integração vertical } \\
\text { protege as condições } \\
\text { superiores de } \\
\text { concorrência. }\end{array}$ & $\begin{array}{l}\text { Recursos estratégicos, específicos e } \\
\text { difíceis de serem mensurados } \\
\text { aumentam a possibilidade de perda de } \\
\text { valor, oportunismo e contratos } \\
\text { incompletos. }\end{array}$ \\
\hline $\begin{array}{l}\text { Hipótese } \\
\text { testável }\end{array}$ & $\begin{array}{l}\text { Maior nível de } \\
\text { especificidade de ativos } \\
\text { implica em uma maior } \\
\text { integração vertical ou } \\
\text { contratos de longo } \\
\text { prazo. }\end{array}$ & $\begin{array}{l}\text { Dificuldade para } \\
\text { medir atributos } \\
\text { dentro da empresa. } \\
\text { Direitos de } \\
\text { propriedade são } \\
\text { colocados com } \\
\text { quem oferece } \\
\text { garantias. }\end{array}$ & $\begin{array}{l}\text { Alto nível de recursos } \\
\text { não imitáveis } \\
\text { demanda integração } \\
\text { vertical. }\end{array}$ & $\begin{array}{l}\text { Recursos estratégicos, específicos e } \\
\text { difíceis de serem mensurados requerem } \\
\text { estruturas mais integradas } \\
\text { verticalmente. }\end{array}$ \\
\hline $\begin{array}{l}\text { Processo } \\
\text { Principal }\end{array}$ & $\begin{array}{l}\text { Características das } \\
\text { transações determinam } \\
\text { a estrutura de } \\
\text { governança. }\end{array}$ & $\begin{array}{l}\text { Dificuldade de } \\
\text { mensuração } \\
\text { determina a } \\
\text { interação vertical e } \\
\text { horizontal, bem } \\
\text { como a estrutura } \\
\text { interna da firma. } \\
\end{array}$ & $\begin{array}{l}\text { Capacidades e } \\
\text { recursos distintos } \\
\text { levam à vantagem } \\
\text { competitiva } \\
\text { sustentável. }\end{array}$ & $\begin{array}{l}\text { Recursos estratégicos, atributos de } \\
\text { transação e dificuldades de mensuração } \\
\text { determinam a melhor estrutura de } \\
\text { governança. }\end{array}$ \\
\hline $\begin{array}{l}\text { Organiza } \\
\text { ção segue } \\
\text { o racional }\end{array}$ & $\begin{array}{l}\text { Estrutura de governança } \\
\text { resulta da perspectiva } \\
\text { de alinhamento com os } \\
\text { atributos de transação e } \\
\text { pressupostos } \\
\text { comportamentais. } \\
\text { Minimização de custos } \\
\text { de transação. } \\
\text { Decisão é tomada ex- } \\
\text { ante, considerando os } \\
\text { riscos ex-post. }\end{array}$ & $\begin{array}{l}\text { Resultados da } \\
\text { estrutura } \\
\text { organizacional } \\
\text { interna a partir da } \\
\text { perspectiva de } \\
\text { maximização de } \\
\text { valor. } \\
\text { Decisão é tomada a } \\
\text { qualquer momento }\end{array}$ & $\begin{array}{l}\text { Capacidades e } \\
\text { recursos devem ser } \\
\text { mantidos e } \\
\text { controlados. } \\
\text { Garantias de direito } \\
\text { de propriedade são } \\
\text { necessárias para } \\
\text { explorar } \\
\text { oportunidades. } \\
\text { Decisão é tomada ex- } \\
\text { ante para gerar } \\
\text { recursos e } \\
\text { capacidades } \\
\text { superiores ex-post. }\end{array}$ & $\begin{array}{l}\text { A proteção e sustentação de vantagem } \\
\text { competitiva depende da escolha de } \\
\text { estruturas de governança que levem em } \\
\text { consideração os atributos de transação, } \\
\text { a sua mensurabilidade, bem como a } \\
\text { condição do recurso estratégico } \\
\text { envolvido. }\end{array}$ \\
\hline
\end{tabular}

Fonte: Elaborado pela autora, a partir de Zylbersztajn (2005). 
Outra importante aplicação da VBR na consideração dos limites da firma está relacionada com a avaliação de possíveis fusões, aquisições ou alianças estratégicas. De acordo com Das e Teng (2000), a RBV considera as fusões, aquisições e alianças como estratégias usadas para acessar os recursos de outras firmas, com o propósito de obter vantagens competitivas e valores que, de outra maneira, não estariam disponíveis. Existem, então, dois motivos distintos para as firmas realizarem alianças estratégicas, fusões ou aquisições: obter recursos ou reter e desenvolver seus próprios recursos pela combinação deles com outros. Na visão de Wernerfelt (1984), considerando a utilização da VBR para a avaliação de possíveis fusões, aquisições ou alianças, idealmente, deveriam ser investigadas questões relacionadas a quais recursos uma dada firma "alvo" possui, quais deles podem trazer vantagem para a empresa, quais os custos de obtenção e quanto a empresa pode pagar.

É valido notar, ainda, que o controle assume papel fundamental nas três abordagens. Pelo lado da VBR, é necessário que recursos estratégicos sejam controlados para manterem sua condição de nãomobilidade. Já, pela ECT, o controle se relaciona mais a minimização de condição de incerteza. Neste sentido, Zylbersztajn (2009, p. 9) observa que "[...] com relação à incerteza [...], inesperados choques externos [...] podem ter consequências reais imprevistas. Portanto, a incerteza motiva a necessidade de um controle mais intenso". Já pela ECM, os direitos de controle surgem como elemento influenciador na decisão de integrar. Hart e Moore (1990) observam que a necessidade ou não de posse de direitos de controle é fundamental para escolher a estrutura de governança adequada na proteção dos direitos de propriedade. Conforme eles, a obtenção de lucros a partir de uma segunda firma (profit stream) pode ser realizada por contratos, mas se o objetivo é ter controle precisa integrar suas atividades (residual control rights). Portanto, o controle, mesmo direcionado a redução de mobilidade de recursos, permite que as respostas em condições de incerteza e proteção de direitos de propriedade sejam mais efetivas.

Percebe-se, portanto, que a perspectiva de complementaridade entre a TCT, TCM e VBR mostrase válida, uma vez que identificar os recursos estratégicos da firma não é o suficiente para a criação e captura de valor. A consideração da TCT e TCM vem no sentido de contribuir para sanar essa crítica, indicando como as estruturas tenderão a se configurar, de forma a assegurar direitos de propriedade e impedir a captura de valor nas transações. Nesse âmbito, a consideração da TCT e TCM aponta a coordenação como mecanismo não só para reduzir custos de transação, mas também para obter e sustentar condições competitivas superiores.

\section{CONSIDERAÇÕES FINAIS}

O objetivo deste artigo foi o de compreender como recursos estratégicos na VBR, ativos específicos na ECT e ativos mensuráveis pela ECM podem influenciar, em sua complementaridade, a escolha de estruturas de governança.

Para tanto, inicialmente, buscou-se realizar uma análise comparativa entre a ECT e a ECM, com base em alguns pressupostos levantados prioritariamente por Zylbersztajn (2005). Observou-se que, na ECT, o maior nível de especificidade de ativos, resulta em maior incerteza nos resultados, demandando a integração vertical devido a possibilidade de maior controle sobre os ativos envolvidos. A ECM, por sua vez, propõe que a integração vertical deve ser utilizada quando a mensuração é difícil e os direitos de propriedade não são claramente definidos. A perspectiva complementar entre essas abordagens indica que a integração vertical pode ser escolhida quando os ativos específicos envolvidos na transação se envolvem em dificuldades efetivas de mensuração, em que a utilização de contratos não é capaz de garantir os direitos de propriedade e evitar a possibilidade de dissipação de valor.

Em um segundo momento, visando alcançar um raciocínio gradual para alcançar o objetivo proposto, realizou-se uma análise conjunta da ECT com a VBR. Nesse aspecto, a complementaridade foi evidenciada a partir da constatação de que recursos estratégicos, estudados pela VBR, podem fornecer as bases para a escolha adequada da estrutura de governança a ser utilizada pela empresa, ao passo em que essas estruturas são escolhidas, com o intuito de proteger e obter vantagens competitivas sustentáveis a partir desses recursos.

Por fim, ao se analisar conjuntamente as três abordagens, o que se constitui o foco principal deste trabalho, ficou evidente que proteger recursos estratégicos pode gerar custos de transação e de mensuração, demandando estruturas de governança específicas. Dito de outra forma, a posse de recursos estratégicos pode caracterizar direito de propriedade que necessita ser protegido por mecanismos legais ou estruturais, contemplados pela ECT e ECM, que minimizem a perda de valor e garantam os direitos de propriedade sobre esses recursos. Nesse aspecto, vale salientar que tantos ativos específicos (ECT) e difíceis de serem mensurados (ECM), quanto recursos estratégicos (VBR) podem aumentar a possibilidade de perda de valor, oportunismo e contratos incompletos, demandando estruturas mais integradas verticalmente. Em última instância, a proteção e sustentação de vantagens competitivas se darão por meio de estruturas de governança que levem em consideração o seu alinhamento com atributos de transação e pressupostos comportamentais (ECT), a mensurabilidade dos ativos específicos envolvidos (ECM) e a sua condição de competitividade (VBR). 
No entanto, é válido destacar algumas questões que indicam limitações para esta investigação. Uma delas refere-se a carência de estudos que discutam aspectos complementares das abordagens aqui discutidas. Apesar de algumas pesquisas evidenciarem pontos de complementaridade entre a ECT e VBR e, em menor instância, entre a ECT e a ECM, não são observados estudos que discutam essas três abordagens conjuntamente, considerando sua influência na determinação dos limites da firma. Ademais, carece-se de pesquisas empíricas para corroborar os aspectos teóricos discutidos. Justifica-se, entretanto, a importância de um primeiro passo para efetivar as possibilidades de conexão entre essas abordagens, bem como possibilitar o avanço na discussão teórica. Sendo assim, futuros estudos sobre a temática podem ser bemvindos na tentativa de aprofundar os pressupostos teóricos envolvidos na complementaridade das abordagens discutidas, minimizando as suas limitações individuais, além de fortalecer a discussão dos determinantes dos limites da firma.

\section{REFERÊNCIAS}

Argyres, N., Zenger, T. (2008) Capabilities, transaction costs, and firm boundaries: a dynamic perspective and integration. Social Science Research Network $(S S R N)$. Available at SSRN: $\langle\mathrm{Be}\rangle$, Jun.

Barney, J.(1991) Firm resources and sustained competitive advantage. Journal of management, 17(1), 99-120.

Barzel, Y.(2005) A Theory of Organizations to Supersede the Theory of the Firm, 2001.

Organizational Forms and Measurement Costs. Journal of Institutional and Theoretical Economics, 161, 357-373.

.(2003) Property rights in the firm. In: Anderson, T. L. Mcchesney,

F.S. Property rights: cooperation, conflict, and law. Princeton University.

.(2003) Standards and the form of agreement. In: 3rd International Society for New

Institutional Economics. Budapeste, Hungria.

. (2001) Theory of organizations to supersede the theory of the firm. Working paper.

Breitenbach, R., Silva, A. da.(2010) Nova Economia Institucional (NEI): Estado de Arte nas (In) Aplicações ao Rural. In.: Congressso da Sociedade Brasileira de Economia e Sociologia Rural - Sober. "Economia e Gestão do Agronegócio", 48 Anais... Campo Grande/MT, 25 a 28 de Junho.
Carvalheiro, E. M. et al.(2004) Uma análise dos contratos utilizando a técnica de análise de correspondência. In: EnAnpad, 28. Curitiba/PR. Rio de Janeiro.

Coase, R. H.(1937) The nature of the firm. Economica, London, New Series, 4(16), 386-405, Nov.

Combs, J. G., Ketchen, D. J. (1999) Explaining interfirm cooperation and performance: toward a reconciliation of prediction from the resourcebased-view and organizational economics. Strategic Management Journal, 20, 867-888.

Das, T. K., Teng, B. S.(2000) A resource-based view of strategic alliances. Journal of Management, 26(1), 31-61.

Farina, E. M. Q., Azevedo, P. F. de., Saes, M. S. M.(1997) Competitividade: mercado, estado $e$ organizações. ( $1^{\mathrm{a}}$ ed.) São Paulo: Editora Singular.

Ferreira, G. M. V. et. al.(2005) A economia dos custos de transação sob uma análise crítica: perspectivas de aplicação no agronegócio. In: Congresso da Sober

"Instituições, Eficiência, Gestão e Contratos no Sistema Agroindustrial", 43. Anais...

Ribeirão Preto, 24 a 27 de Julho.

Foss, N.J. (2005) Strategy, economic, organization, and the knowledge economy: the coordination of firms and resources. Oxford: Oxford University Press.

Garcia, F. C., Bronzo, M. (2000) As bases epistemológicas do pensamento administrativo

convencional e a crítica à teoria das organizações. Recuperado em: 01 març. 2014, de: <www.anpad.org.br/eneo/2000/dwn/eneo200002.pdf>.

Gomes, F.G. (2004) A nova economia institucional (NEI) e o (Sub) desenvolvimento econômico brasileiro: limites e impossibilidades de interpretação. In: Sep - Encontro Nacional de Economia Política, Uberlândia. Anais... Uberlândia.

Ghoshal, S., Moran, P.(1996) Bad for practice: a critique of the transaction cost theory. Academy of Management Review, 21(1), 13-47, Jan.

Hart, O., Moore, J. (1990) Property rights and the nature of the firm. The Journal of Political Economy, 98(6), 1119-1158.

Jacobides, M. G., Winter, S. G. (2005) Co-evolution of capabilities and transaction costs: explaining the institutional structure of production. Strategic Management Journal, 26, 395-413. 
Nova Economia Institucional: Vertentes Complementares

Kohls, V.K., Fensterseifer, J.E.(2004) Estratégicas competitivas de empresas agroalimentares: estudo de casos na zona sul do RS. In: Enanpad-Encontro da Anpad, 28, Curitiba/PR. Rio de Janeiro.

Langlois, R.N.(1992) Transaction-cost economics in real time. Oxford Journal - Industrial and Corporate Change, 1(1), 99-127.

Mahoney, J.(2001) A resource-based theory of sustainable rents. Journal of Management, 27, 651660.

Ménard, C. (2004) The economics of hybrid organizations. Journal of Institutional and Theoretical Economics, JIT 160, 345-376.

Mintzberg, H. et. al.(2000) Safári de estratégia. Porto Alegre: Bookman.

Mizumoto, F. M., Zylbersztajn, D.(2006) A coordenação simultânea de diferentes canais como estratégia de distribuição adotada por empresas da avicultura de postura. Organizações Rurais \& Agroindustriais, Lavras, 8(2), 147-159.

Montgomery, C. A., Porter, M. E.(1998) Estratégia: a busca da vantagem competitiva. Rio de Janeiro: Campus.

Nickerson, J.A. (2003) Toward a positioning economizing theory of strategy. Mimeo. John M. Olin School of Business. Washington University in Saint Louis Campus 9.

Zenger, T.R.(2004) A knowledge-based theory of the firm -

The problem-solving perspective. Organization Science, 15(6), 617-632, Nov.

North, D.C.(2006) Custos de transação, instituições e desempenho econômico. Rio de Janeiro: Instituto Liberal, 38.

.(1991) Institutions. Journal of Economic Perspective, 5(1), 97-112, Winter.

Penrose, E.T.(1959) The theory of the growth of the firm. New York: Wiley.

Peteraf, M.A.(1993) The cornerstones of competitive advantage: a resource based view. Strategic Management Journal, 14, 179-191.

Poppo, L., Zenger, T.(1998) Testing alternative theories of the firm: transaction cost, knowledge- based, and measurement explanations for make-orbuy decisions in information services. Strategic Management Journal, 19, 853-877.

Saes, M.S.M. (2009) Estratégias de diferenciação e apropriação da quase-renda na agricultura: a produção de pequena escala. São Paulo: Annablume, Papesp.

Sologuren, L. J., De Paula, G. M.(2004) Integração vertical, grupos estratégicos e competitividade: o caso do sistema agroindustrial da soja no Brasil. In: EnAnpad -Encontro da Anpad, 28, Curitiba/PR. Rio de Janeiro.

Teece, D., Pisano, G., Shuen, A.(!997) Dynamic capabilities and strategic management. Strategic Management Journal, 18(7), 509-533.

Wernerfelt, B.(1984) A resource-based view of the firm. Strategic Management Journal, 5(2), 171180.

Williamson, O. E. (1975) Markets and hierarchies: analysis and antitrust implications. New York: Free Press.

(1985) The economic institutions of capitalism: firms, markets, relational contracting. New York: Free Press.

(1991) Comparative economic organization: the analysis of discrete structural alternatives. Administrative Science Quarterly, 36(2), 269-296.

(1996) The mechanisms of governance. New York: Oxford University Press.

.(1999) Strategy research: governance and competence perspective. Strategic Management Journal, 20(12), 1087-1108, December.

(2008)Transaction cost economics and organization theory. HBS Conference on Organization Design. December 5-6.

Zylberztajn, D.(2009) Papel dos contraltos na coordenação agro-industrial: um olhar al mercados. In: Souza, J.P. de, Prado, I.N. do Cadeias produtivas: estudos sobre competi e coordenação. (2. Ed.) Maringá: Eduem.

(2005) Measurement costs and governance: bridging perspectives of transaction cost economics. In: International Society for the New Institutional Economics - ISNIE, BarcelonaEspanha. 